\title{
HIGH PERFORMANCE SPUTTERED THERMOELECTRIC JUNCTIONS FOR MICROMECHANICAL DEVICES
}

\author{
R.P. Shea ${ }^{l}$, A.S. Gawarikar ${ }^{1}$, and J.J. Talghader ${ }^{{ }^{*}}$ \\ ${ }^{1}$ University of Minnesota, Minneapolis, Minnesota, USA
}

\begin{abstract}
The deposition and characterization of thin co-sputtered $\mathrm{Bi}_{2} \mathrm{Te}_{3}$ and $\mathrm{Sb}_{2} \mathrm{Te}_{3}$ thermoelectric films of thickness comparable to the carrier mean free path is presented. Measurements of the Seebeck coefficient, resistivity, and thermal conductivity are described. The test microstructures are highly thermally isolated and incorporate a micro-heater and thermoelectric junction. Two compositions of each material have been studied. The $\mathrm{Sb}_{2} \mathrm{Te}_{3}$ shows resistivities of $29.72 \mu \Omega-\mathrm{m}$ and $26.22 \mu \Omega-\mathrm{m}$, Seebeck coefficients of $118 \mu \mathrm{V} / \mathrm{K}$ and $131 \mu \mathrm{V} / \mathrm{K}$, and a thermal conductivity of $1.02 \mathrm{Wm}^{-1} \mathrm{~K}^{-1}$, while the $\mathrm{Bi}_{2} \mathrm{Te}_{3}$ films show resistivities of $5.22 \mu \Omega-\mathrm{m}$ and $6.15 \mu \Omega-\mathrm{m}$, Seebeck coefficients of $-51 \mu \mathrm{V} / \mathrm{K}$ and $50 \mu \mathrm{V} / \mathrm{K}$, and a thermal conductivity of $.88 \mathrm{Wm}^{-1} \mathrm{~K}^{-1}$. The materials systems exhibit thermoelectric figures of merit of $0.93 \times 10^{-3}$ and $1.23 \times 10^{-3}$.
\end{abstract}

\section{INTRODUCTION}

$\mathrm{Bi}_{2} \mathrm{Te}_{3} / \mathrm{Sb}_{2} \mathrm{Te}_{3}$ junctions are among the best thermoelectric devices in existence; however, thin films of these materials are difficult to deposit and utilize in micromachined devices. Boyer and Cisse have shown that the thermoelectric properties degrade at thicknesses below 500nm in epitaxial MJCVD films due to limited mean-free path of carriers [1]. Unfortunately, micromechanical and nanosystems require films that are thinner than this threshold. They also require films that are compatible with common and accessible deposition techniques, such as sputtering or evaporation.

The deposition of thin films of $\mathrm{Bi}_{2} \mathrm{Te}_{3}$ and $\mathrm{Sb}_{2} \mathrm{Te}_{3}$ using methods such as MJCVD [1], flash evaporation [2], and coevaporation $[3,4]$ has been widely studied but limited work has been done on sputtered films of these materials, in particular $\mathrm{Sb}_{2} \mathrm{Te}_{3}$. Various groups have studied co-sputtering of $\mathrm{Bi}_{2} \mathrm{Te}_{3}[5,6]$ as well as reacting alternating films of sputtered $\mathrm{Bi}$ and $\mathrm{Te}$ [7], but to our knowledge, no study exists of thermoelectric junctions of sputtered $\mathrm{Bi}_{2} \mathrm{Te}_{3}$ and $\mathrm{Sb}_{2} \mathrm{Te}_{3}$ thin films incorporated into a micromechanical device.

The fabricated device consists of a highly thermally isolated micro-heater connected to a thermoelectric junction. A diagram of



Figure 1: Conceptual image of the fabricated devices showing layer structure and device layout. this design can be seen in Figure 1. The hot side of the thermoelectric element lies on the same thermally isolated structure as the micro-heater while the cold side lies on the substrate. This allows us to accurately control the temperature difference between the two sides of the junction and therefore characterize its thermoelectric properties. Our thermoelectric films range in thickness from $225 \mathrm{~nm}$ to $272 \mathrm{~nm}$ and the thermal isolation of the micro-heater is on the order of $5 \times 10^{-7} \mathrm{~W} / \mathrm{K}$.

\section{FABRICATION}

The thermoelectric junctions were fabricated using a series of surface micromachining processes followed by a through-wafer etch release using the Bosch process. Fabrication began with an LPCVD low-stress nitride layer which was deposited on both sides of the wafer, but removed from the back side with a $\mathrm{CF}_{4} / \mathrm{O}_{2}$ plasma etch. This layer is intended to provide electrical insulation between the substrate and bond pads. Next, an atomic layer deposition (ALD) film of $\mathrm{Al}_{2} \mathrm{O}_{3}$ was deposited on both sides of the wafer which serves to electrically isolate ensuing layers from the substrate as well as provide structural support and act as an etch stop layer for the final release. Next a Ni layer was deposited to form the micro-heater used to characterize the device. This layer and the following metal and thermoelectric layers were patterned using a lift-off technique. Ti/Pt was then deposited both to form pads for wire bonding and to connect the thermoelectric materials and the micro-heater to these pads. A $\mathrm{Cr} / \mathrm{Au}$ layer was then deposited on top of the $\mathrm{Pt}$ of the bond pads to thicken them for wire bonding.

Thermoelectric films were deposited by RF magnetron cosputtering the base elements. The elemental composition of cosputtered films has been measured on test samples using Rutherford Back Scattering (RBS) for $\mathrm{Bi}_{2} \mathrm{Te}_{3}$ and Energy Dispersion X-ray Spectrometry (EDX) for $\mathrm{Sb}_{2} \mathrm{Te}_{3}$. In this study, the sputtering power of Te was held constant at $27 \mathrm{~W}$ while the sputtering powers of $\mathrm{Sb}$ and $\mathrm{Bi}$ were varied. The films are deposited at a substrate temperature of $260^{\circ} \mathrm{C}$ for in $\mathrm{Bi}_{2} \mathrm{Te}_{3}$ and $230^{\circ} \mathrm{C}$ in $\mathrm{Sb}_{2} \mathrm{Te}_{3}$ as suggested in [8]. The measured $\mathrm{Te}$



Figure 2: Tellurium composition vs Bi/Sb sputtering power for cosputtered $\mathrm{Bi}_{2} \mathrm{Te}_{3}(\square)$ and $\mathrm{Sb}_{2} \mathrm{Te}_{3}(\mathrm{O})$ with Te sputtering power held constant at $27 \mathrm{~W}$. 
composition of films for each compound can be seen in Figure 2. For the Seebeck coefficient, resistivity, and thermal conductivity data presented here, two recipes were used for each material. Batch A used sputtering powers of $22 \mathrm{~W}$ for $\mathrm{Bi}$ and $26 \mathrm{~W}$ for $\mathrm{Sb}$ while Batch B used sputtering powers of $23 \mathrm{~W}$ for $\mathrm{Bi}$ and $27 \mathrm{~W}$ for $\mathrm{Sb}$. In all cases, the sputtering power of Te was $27 \mathrm{~W}$. These values correspond to a sputtering power density of $3.82 \mathrm{~W} / \mathrm{in}^{2}$ at $27 \mathrm{~W}$ for the 3 " targets used. Film thickness was measured using standard profilometry and measured sputtering rates range from 5$6 \mathrm{~nm}$ per minute.

After the thermoelectric films are deposited, a second layer of ALD $\mathrm{Al}_{2} \mathrm{O}_{3}$ was deposited to encapsulate the films during the ensuing etch steps. This layer was then patterned using a $\mathrm{BCl}_{3}$ plasma etch to both define the support structure and plates of the devices and to open vias to enable electrical contact to the bond pads. The back-side $\mathrm{Al}_{2} \mathrm{O}_{3}$ was pattered in the same way to define the etch pits used for release. Finally the devices were released using a through wafer Bosch etch leaving free-standing thermal isolation structures containing micro-heaters and the hot side of thermoelectric junction. The nitride layer is mostly removed during the Bosch etch, but often requires a secondary plasma etch to fully remove. The material, deposition method, and thickness of each layer are seen in Table 1 and a diagram of the device layout can be seen in Figure 1.

Table 1: Material, layer thickness, and deposition technique for sequential fabrication steps.

\begin{tabular}{|c|c|c|}
\hline Material & Thickness $(\mathrm{nm})$ & Technique \\
\hline $\mathrm{LSN}$ & 200 & LPCVD \\
\hline $\mathrm{Al}_{2} \mathrm{O}_{3}$ & 25 & ALD \\
\hline $\mathrm{Ni}$ & 15 & E-Beam Evap. \\
\hline $\mathrm{Ti} / \mathrm{Pt}$ & $5 / 10$ & E-Beam Evap. \\
\hline $\mathrm{Cr} / \mathrm{Au}$ & $15 / 185$ & E-Beam Evap. \\
\hline $\mathrm{Bi}_{2} \mathrm{Te}_{3}$ & $253(\mathrm{~A}) 272(\mathrm{~B})$ & RF Sputter \\
\hline $\mathrm{Sb}_{2} \mathrm{Te}_{3}$ & $229(\mathrm{~A}) 225(\mathrm{~B})$ & RF Sputter \\
\hline $\mathrm{Al}_{2} \mathrm{O}_{3}$ & 25 & ALD \\
\hline
\end{tabular}

\section{CHARACTERIZATION}

Temperature Coefficient of Resistivity

An important factor in the characterization of the thermoelectric films is the temperature coefficient of resistance (TCR) of the micro-heater. The TCR, $\alpha$, is given by

$$
R(T)=R\left(T_{0}\right)(1+\alpha \Delta T)
$$

In our case this was measured by placing the device die on a standard Peltier cooler/heater and measuring the device resistance compared to the temperature measured by a reference thermistor. The TCR measured was $.31 \% / \mathrm{K}$ for the $\mathrm{Ni}$ micro-heaters and $.12 \% / \mathrm{K}$ for $\mathrm{Ni} / \mathrm{Fe}$.

\section{Seebeck Coefficient}

The Seebeck coefficient of the released devices was measured by varying the temperature of the hot junction using the microheater and monitoring this temperature change using the resistance of the heater. The Seebeck coefficient, $\sigma$, is given by

$$
\sigma=\frac{\Delta V}{\Delta T}
$$

where $\Delta \mathrm{V}$ is measured and $\Delta \mathrm{T}$ was calculated from the change in resistance measured as the current varies.

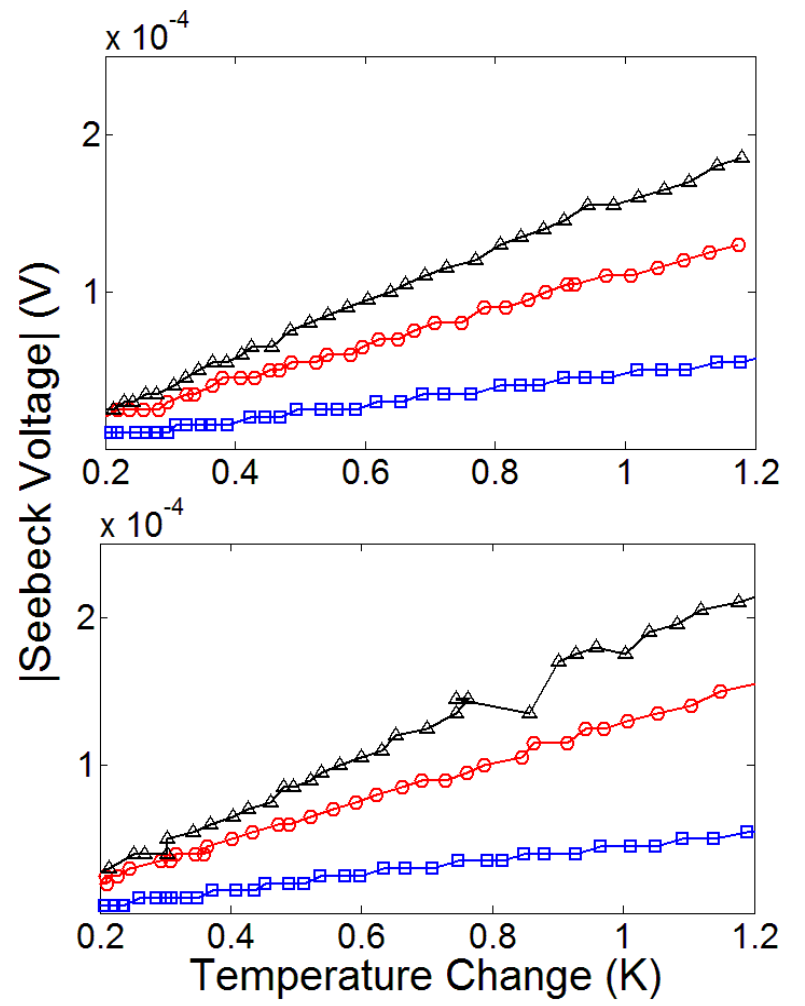

Figure 3: Seebeck voltage vs. temperature change for released Batch A (bottom) and Batch B (top) thermoelectric junctions (4), $\mathrm{Sb}_{2} \mathrm{Te}_{3}$ test structures (O), and $\mathrm{Bi}_{2} \mathrm{Te}_{3}$ test structures ( $\square$ ).

To measure the Seebeck coefficient of devices we contacted the bond pads of released structures using four probe tips. The micro-heater was connected to a source meter which allows us to source a variable current to the heater while measuring its resistance. The thermoelectric element was connected to a voltage meter via a low noise pre-amplifier to measure the resulting change in Seebeck voltage. The temperature change, $\Delta \mathrm{T}$, of the microheater, and therefore the hot side of the junction can then be calculated using Equation 1. From Equation 2 we can see that the Seebeck coefficient is directly related to the slope of the Seebeck voltage vs. temperature change plot seen in Figure 3. We have tested both thermoelectric junctions, like those seen in Figure 4, as well as test structures comprised of single materials connected to Pt lines. In Figure 3, the absolute value of the Seebeck voltage is plotted for comparison and the calculated Seebeck coefficient values for both batches are shown in Table 2 .

Table 2: Seebeck coefficents measured for test structures and junctions for each recipe.

\begin{tabular}{|c|c|c|c|}
\hline Material & Batch & $\begin{array}{c}\text { Power Ratio } \\
(\mathrm{Sb}, \mathrm{Bi}) / \mathrm{Te}(\mathrm{W})\end{array}$ & $\begin{array}{c}\text { Seebeck } \\
\text { Coef. }\end{array}$ \\
\hline $\mathrm{Sb}_{2} \mathrm{Te}_{3}$ & A & $26 / 27$ & $118 \mu \mathrm{V} / \mathrm{K}$ \\
\hline $\mathrm{Bi}_{2} \mathrm{Te}_{3}$ & $\mathrm{~A}$ & $22 / 27$ & $-51 \mu \mathrm{V} / \mathrm{K}$ \\
\hline $\mathrm{Junction}_{\mathrm{Sb}} \mathrm{Te}_{3}$ & A & $26 / 27 \& 22 / 27$ & $168 \mu \mathrm{V} / \mathrm{K}$ \\
\hline $\mathrm{Bi}_{2} \mathrm{Te}_{3}$ & $\mathrm{~B}$ & $27 / 27$ & $133 \mu \mathrm{V} / \mathrm{K}$ \\
\hline $\mathrm{Junction}^{\mid}$ & B & $23 / 27$ & $-50 \mu \mathrm{V} / \mathrm{K}$ \\
\hline
\end{tabular}




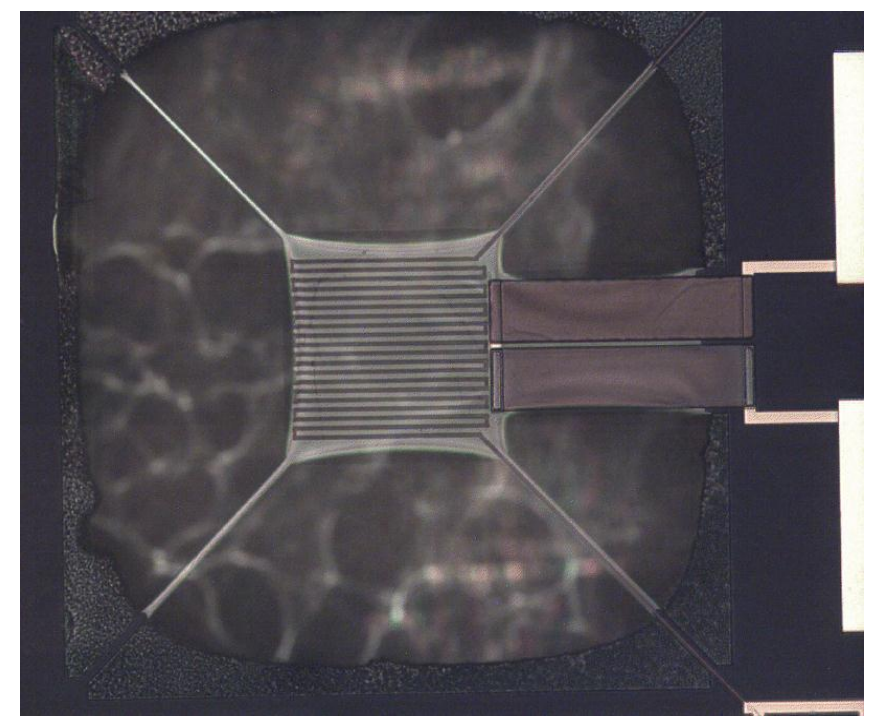

Figure 4: Optical image of the released device with the microheater seen on the center plate and the thermoelectric junction to the right of the plate.

\section{Thermal Conductivity}

The thermal conductivity $(\kappa)$ of our materials was characterized using test structures like that seen in Figure 5. This structure consists of a thermally isolated micro-heater with wide legs composed of mostly the thermoelectric material being studied. With this geometry, the dominant heat transfer mechanism is thermal conduction through the material of interest. When placed in vacuum, conduction through air and convection can be ignored and the heat balance equation of the structure simplifies to

$$
\mathbf{I}^{2} \mathbf{R}=\mathbf{G} \Delta \mathbf{T}
$$

Testing was done on samples using the Batch A recipe and using a $\mathrm{NiFe}$ micro-heater having a TCR of $.12 \% / \mathrm{K}$. Again, we sourced a varying current while measuring the resistance of the micro-heater and the total thermal conductance of the structure can be calculated

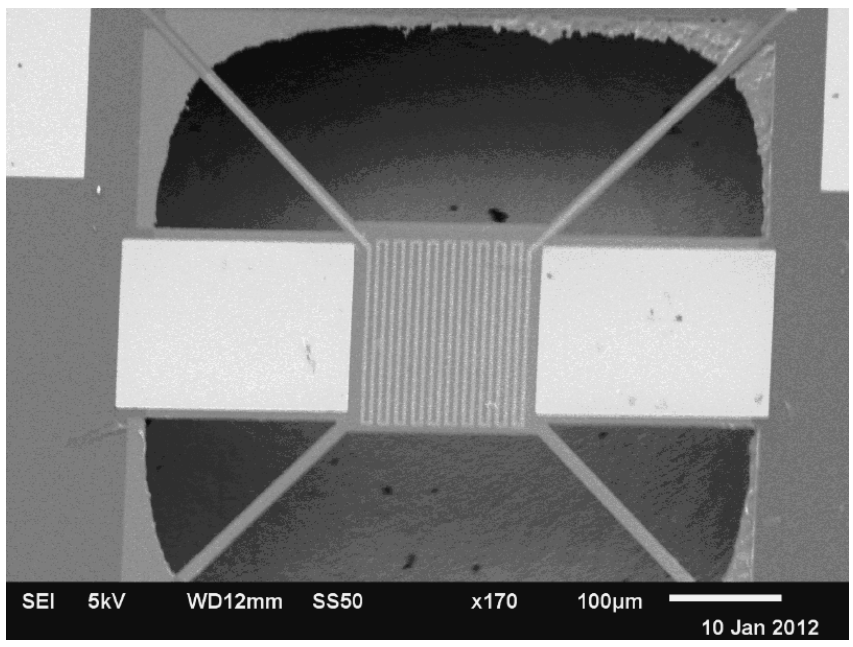

Figure 5: SEM micrograph of the test structures used to characterize the thermal conductivity of the thermoelectric materials. A micro heater supported by large films of the material being studied.

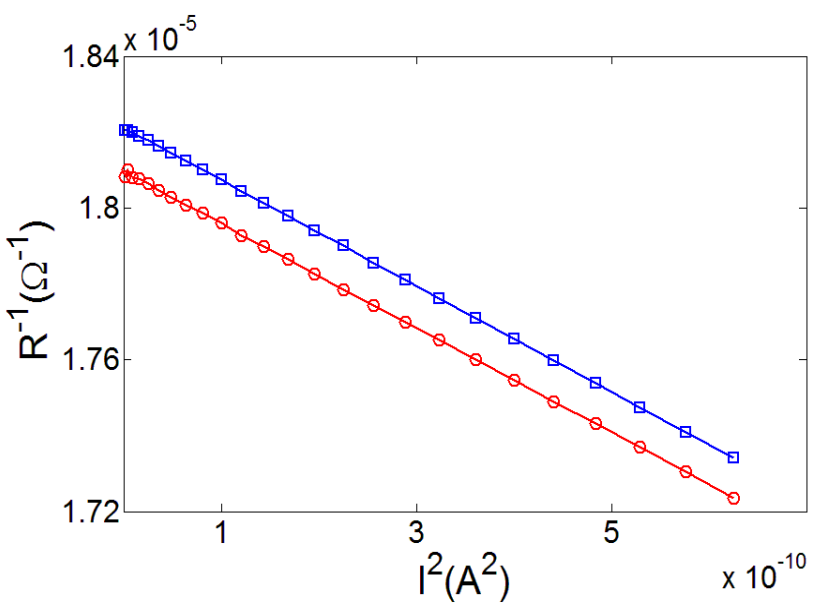

Figure 6: Thermal conductivity data $\left(I^{2}\right.$ vs. $\left.R^{-1}\right)$ for $\mathrm{Sb}_{2} \mathrm{Te}_{3}$ (०) and $\mathrm{Bi}_{2} \mathrm{Te}_{3}$ ( $\square$ ) test structures for films using the Batch $\mathrm{A}$ recipe.

as the micro-heater TCR divided by the slope of the $\mathrm{I}^{2}$ vs. $\mathrm{R}^{-1}$ plot seen in Figure 6. In order to extract the $\kappa$ values of our materials from the overall thermal conductance of the structure, we made a few assumptions about the other materials involved. We have assumed that $\kappa=2.6 \mathrm{Wm}^{-1} \mathrm{~K}^{-1}$ for $\mathrm{ALD} \mathrm{Al}_{2} \mathrm{O}_{3}$, a value that has been measured previously by our group [9], and that $\kappa=25 \mathrm{Wm}^{-1} \mathrm{~K}^{-1}$ for $\mathrm{Ni} / \mathrm{Fe}$. These assumptions are conservative, but have little impact on the final calculation due to the relatively small amount of $\mathrm{Ni} / \mathrm{Fe}$ in the support structure. The thermal conductance due to convection, conduction through air, and radiation were assumed to be negligible. Our final calculated values for these materials are $\kappa=.88 \mathrm{Wm}^{-1} \mathrm{~K}^{-1}$ for $\mathrm{Bi}_{2} \mathrm{Te}_{3}$ and $\kappa=1.02 \mathrm{Wm}^{-1} \mathrm{~K}^{-1}$ for $\mathrm{Sb}_{2} \mathrm{Te}_{3}$.

The thermal conductivity of devices such as those seen in Figure 4 was measured at around $5 \times 10^{-7} \mathrm{~W} / \mathrm{K}$ for both batches. This is a higher value than expected given the measured $\kappa$ values for the thermoelectric materials. We suspect that this is due to significant thermal conductivity due to radiation in our devices which becomes more apparent for lower $\mathrm{G}$ structures. The infrared absorption of $\mathrm{Ni}$ micro-heater devices was measured using an FTIR microscope and revealed an average absorption of $27 \%$ in the $8-12 \mu \mathrm{m}$ peak room-temperature thermal emission range. Using the Stephan Boltzman Law we can estimate the thermal conductance due to radiation $1.32 \times 10^{-7} \mathrm{~W} / \mathrm{K}$ which is approximately $15 \%$ of the total thermal conductance of our test structures. This means that our calculated $\kappa$ values may have been somewhat conservative, as some of the thermal conductance attributed to the films was actually due to radiation. Unfortunately, we were unable to measure $\kappa$ values for the Batch B devices, but given the relatively small deviation in $\kappa$ with small changes in composition for this material system [10], we assume the same $\kappa$ values for both batches when calculating the figure of merit. This is a non-ideal assumption but given the conservative nature of our calculation, we felt it was reasonable.

\section{Resistivity}

Film resistivity $(\rho)$ is defined as

$$
\rho=\frac{\mathbf{R A}}{\mathbf{L}}
$$

Where $\mathrm{R}$ is the resistance of the film in Ohms, $\mathrm{L}$ is the length, and A is the cross sectional area of the film. Since it is impossible to isolate the resistivity of the individual materials while testing 
junctions, electrical testing included both thermoelectric junctions and test structures which were simply long resistors of single materials. The resistance test structures consisted of $1730 \mu \mathrm{m}$ long, $3 \mu \mathrm{m}$ wide resistors contacted in a four point resistance measurement test structure. Due to lift-off issues with $3 \mu \mathrm{m}$ widths, the Batch $\mathrm{A} \mathrm{Sb}_{2} \mathrm{Te}_{3}$ resistivity was tested on $5 \mu \mathrm{m}$ wide resistors of the same length. Film thicknesses are given in Table 1. Resistance was measured using a current of $10 \mu \mathrm{A}$. The resistivities calculated for Batch A are 5.22 $\mu \Omega-\mathrm{m}$ for $\mathrm{Bi}_{2} \mathrm{Te}_{3}$ and $29.72 \mu \Omega-\mathrm{m}$ for $\mathrm{Sb}_{2} \mathrm{Te}_{3}$. For Batch B we calculated $6.15 \mu \Omega-\mathrm{m}$ for $\mathrm{Bi}_{2} \mathrm{Te}_{3}$ and $26.22 \mu \Omega-\mathrm{m}$ for $\mathrm{Sb}_{2} \mathrm{Te}_{3}$.

The resistance of unreleased thermoelectric junctions like those shown in Figure 4 was tested over a variety of film widths. The measured values were significantly higher than expected given the resistivity values previously measured on test structures. We suspect this is due to a contact resistance issue since the resistance values tend to converge to the expected value in the narrower junctions where the film geometry is closer to that of the test structures. Also, for reasons we do not yet understand, the resistance of the junctions drops significantly after etch release, bringing them to within $15 \%$ of the expected value. An example are the $54 \mu \mathrm{m}$ wide Batch A junctions which have an expected resistance of $1164 \Omega$ given their geometry and measured resistivity. Before release the average resistance measured is $1727 \Omega$ while this drops to $1304 \Omega$ after release.

Figure of Merit

The thermoelectric figure of merit $(Z)$ is defined as

$$
Z=\frac{\left(\sigma_{p}-\sigma_{n}\right)^{2}}{\left[\left(\kappa_{\rho} \rho_{\rho}\right)^{2}+\left(\kappa_{n} \rho_{n}\right)^{2}\right]^{\frac{1}{2}}}
$$

which simplifies to $z=\sigma^{2} \kappa^{-1} \rho^{-1}$ when dealing with a single material [10]. Table 3 shows the measured parameters for each film and the calculated $\mathrm{Z}$ value. Combining the properties of the two materials using Equation 3 we calculate an overall $\mathrm{Z}$ value of $0.93 \times 10^{-3}$ for the Batch A material system $1.23 \times 10^{-3}$ for the batch B material system.

Table 3: Measured resistivity ( $\rho)$, thermal conductivity $(\kappa)$, Seebeck coefficient $(\sigma)$, and calculated figure of merit (Z) for the films presented. The * on the Batch $B$ values indicates that the values were assumed equal to Batch $A$ as explained in the text.

\begin{tabular}{|l|l|l|l|l|}
\hline Recipe & $\rho(\mu \Omega-\mathrm{m})$ & $\kappa(\mathrm{W} / \mathrm{mK})$ & $\sigma(\mu \mathrm{V} / \mathrm{K})$ & $\mathrm{Z}^{*} 10^{4}$ \\
\hline $\mathrm{Sb}_{2} \mathrm{Te}_{3} \mathrm{~A}$ & 29.72 & 1.02 & 118 & 4.59 \\
\hline $\mathrm{Sb}_{2} \mathrm{Te}_{3} \mathrm{~B}$ & 26.22 & $1.02^{*}$ & 133 & 6.61 \\
\hline $\mathrm{Bi}_{2} \mathrm{Te}_{3} \mathrm{~A}$ & 5.22 & .88 & -51 & 5.66 \\
\hline $\mathrm{Bi}_{2} \mathrm{Te}_{3} \mathrm{~B}$ & 6.15 & $.88^{*}$ & -50 & 4.62 \\
\hline
\end{tabular}

\section{CONCLUSIONS}

Microstructures have been fabricated with a high degree of thermal isolation, $\mathrm{G} \sim 5 \times 10^{-7}$, which contain a micro-heater and $\mathrm{Sb}_{2} \mathrm{Te}_{3} / \mathrm{Bi}_{2} \mathrm{Te}_{3}$ thermoelectric junction. The thermoelectric properties, Seebeck coefficients, resistivities, and thermal conductivities of these materials have been measured for two different compositions of each material. The resulting figures of merit for these materials systems are $0.93 \times 10^{-3}$ and $1.23 \times 10^{-3}$.

These values are sufficient for applications such as micro-coolers, infrared detector readouts, and temperature controllers using films thin enough for MEMS-based devices.

\section{ACKNOWLEDGEMENTS}

The authors would like to thank DARPA MTO for their support under Army Research Office contract W911QX-12-C0002. The views expressed are those of the authors and do not reflect the official policy or position of the Department of Defense or the U.S. Government. Approved for public release, distribution unlimited.

\section{REFERENCES}

[1] A. Boyer and E. Cissé, "Properties of thin film thermoelectric materials: application to sensors using the Seebeck effect," Materials Science and Engineering: B, 13, 2 (1992).

[2] N.G. Patel and P.G. Patel, "Thermoelectric cooling efficiency in a $\mathrm{p}-\mathrm{Sb}_{2} \mathrm{Te}_{3}-\mathrm{n}-\mathrm{Bi}_{2} \mathrm{Te}_{3}$ thin film thermocouple," Solid-State Electronics, 35, 9 (1992).

[3] H. Zou, D.M. Rowe, and S.G.K. Williams, "Peltier effect in a co-evaporated $\mathrm{Sb}_{2} \mathrm{Te}_{3}(\mathrm{P})-\mathrm{Bi}_{2} \mathrm{Te}_{3}(\mathrm{~N})$ thin film thermocouple," Thin Solid Films, 408, 1-2 (2002).

[4] L.M. Goncalves, P. Alpium, G. Min, D.M. Rowe, C. Couto, and J.H. Correia, "Optimization of $\mathrm{Bi}_{2} \mathrm{Te}_{3}$ and $\mathrm{Sb}_{2} \mathrm{Te}_{3}$ thin films deposited by co-evaporation on polyimide for thermoelectric applications," Vacuum, 82, 12 (2008).

[5] D. Kim and G. Lee, "Effect of rapid thermal annealing on thermoelectric properties of bismuth telluride films grown by co-sputtering," Materials Science and Engineering: B, 131, 13 (2006).

[6] H. Bottner, J. Nurnus, A. Gavrikov, G. Kuhner, M. Jagle, C. Kunzel, D. Eberhard, G. Plescher, A. Schubert, K.-H. Schlereth, "New thermoelectric components using microsystem technologies," Journal of Microelectromechanical Systems, 13, 3, (2004).

[7] C. Liao and T. She, "Preparation of bismuth telluride thin films through interfacial reacting," Thin Solid Films, 515, 2021 (2007).

[8] A. Gross, G. Hwang, B. Huang, H. Yang, N. Ghafouri, H. Kim, C. Uher, M. Kaviany, K. Najafi, "High-performance micro scale thermoelectric cooler: An optimized 6-stage cooler," Solid-State Sensors, Actuators and Microsystems Conference, Denver, CO, 6/21-25/09, IEEE, Piscataway (2009), pp. 2413-2416.

[9] N. T. Gabriel and J. J. Talghader, "Thermal conductivity and refractive index of hafnia-alumina nanolaminates," Journal of Applied Physics, 110, 4, (2011).

[10] D.M. Rowe, CRC Handbook of Thermoelectrics, CRC Press, Boca Raton, 1995.

\section{CONTACT}

*J.J. Talghader, tel: +1-612-625-4524; joey@umn.edu 